\title{
O ENSINO NOS ANOS DE ALFABETIZACAO MATEMÁTICA
}

\author{
Rosemara Perpetua Lopes ${ }^{1}$
}

\begin{abstract}
RESUMO
Apresenta-se uma pesquisa que tem como objetivo geral investigar o tratamento conferido à alfabetização matemática nos dois primeiros anos escolares, com vistas à melhoria do ensino dos conteúdos dessa área no Ensino Fundamental I. O estudo adquire relevância em face da dificuldade dos alunos em aprender Matemática, do baixo rendimento que apresentam nesse campo, da escassez e precariedade do tratamento conferido à mesma na Educação Infantil, da falta de familiaridade do aluno do curso de Pedagogia com o conhecimento matemático e de domínio sobre o ensino e a aprendizagem matemática nos primeiros anos escolares, especialmente nos de alfabetização. Do ponto de vista metodológico, trata-se de uma pesquisa de cunho qualitativo, realizada por análise documental, tendo como fontes projetos políticopedagógicos de escolas municipais de Jataí, Estado de Goiás. O desenvolvimento inclui bibliográfica na etapa inicial, a partir de fundamentação teórica pertinente à alfabetização matemática e aos conhecimentos do professor que ensina Matemática.
\end{abstract}

Palavras-chave: Ensino fundamental. Alfabetização matemática. Formação de professores.

\section{THE TEACHING IN TIMES OF MATHEMATICAL LITERACY}

\begin{abstract}
One presents a research that has as main objective to investigate the treatment given to mathematical literacy in the first two school years, aimed at improving the teaching of the contents of this area in elementary education I. The study acquires relevance due to the difficulty of students to learn mathematics, low efficiency in this field, the scarcity and precariousness of the treatment given to it in kindergarten, the lack of familiarity of the pedagogy course student with the mathematical knowledge and domain of teaching and learning Mathematics in the early school years, especially in the literacy years. From a methodological point of view, it is a qualitative research, carried out by document analysis, having as source political-pedagogical projects of public schools in Jataí, State of Goiás. The development includes bibliographic research in the initial stage, from relevant theoretical foundation pertinent to mathematical literacy and to the educator's knowledge that teaches mathematics.
\end{abstract}

Keywords: Elementary school. Mathematical literacy. Teacher's training.

\footnotetext{
${ }^{1}$ Docente do curso de Pedagogia da Universidade Federal de Goiás (UFG) - Regional Jataí. Email: rosemaralopes@gmail.com
} 


\section{Mtinerarilus Devista Eletrônica da Pós-Graduação

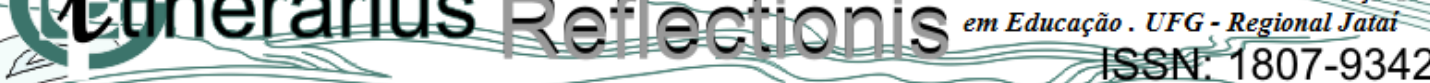 v. 11, n. 2,2015}

\section{INTRODUÇÃO}

Este artigo apresenta resultados preliminares de uma pesquisa que tem como objetivo geral investigar o tratamento conferido à alfabetização matemática nos dois primeiros anos escolares. Seus objetivos específicos consistem em elencar conhecimentos matemáticos que compõem o currículo do primeiro e do segundo ano escolar; identificar práticas de ensino ou situações de aprendizagem matemática presentes nos documentos escolares; analisar a orientação epistemológica subjacente ao ensino de Matemática, se sintática e/ou semântica, categorias criadas a partir de Gómez-Granell (2006).

O estudo adquire relevância na medida em que chama a atenção da comunidade escolar para as particularidades e a importância do ensino de matemática nos dois primeiros anos escolares; contribui para repensar práticas de ensino desse conteúdo nesse período da escolarização, tendo em vista a aprendizagem do aluno e a necessidade de evitar sua exclusão precoce dessa área de conhecimento; gera reflexão sobre a alfabetização matemática e o tratamento metodológico conferido à mesma nos anos iniciais do Ensino Fundamental.

Do ponto de vista metodológico, focalizam-se as escolas municipais da zona urbana de Jataí, Estado de Goiás (GO), cidade com aproximadamente 95.000 habitantes $^{2}$ em 2014, segundo o Instituto Brasileiro de Geografia e Estatística (IBGE). Para atender a essa população, cabe ao município valorizar o trabalho do professor que atua na Educação Infantil e no Ensino Fundamental I, dado o impacto desse período na trajetória escolar do aluno, especialmente em Matemática, área na qual as não-aprendizagens de hoje podem comprometer o ensino de amanhã (por exemplo, o aluno que não aprendeu a multiplicar e a dividir dificilmente aprenderá frações), inclusive em outras áreas, como a Física, que requer conhecimento matemático, podendo gerar reflexos futuros na escolha da profissão.

Assim procedendo, busca-se responder à seguinte questão: que tratamento as escolas municipais urbanas de Jataí conferem ao ensino de matemática nos dois primeiros anos escolares em seus projetos pedagógicos? Estes últimos são concebidos na perspectiva de Silva (2003) e de Veiga (2003).

A esta breve introdução, seguem-se referencial teórico, contendo alguns dos pressupostos que fundamentam o trabalho investigativo; metodologia, em que são explanadas

\footnotetext{
${ }^{2}$ Dados disponíveis em: <http://cod.ibge.gov.br/233II>. Acessado em: 25 fev. 2015.
} 


\section{- Prinerarills Devista Eletrônica da Pós-Gradtuação ¿2 \\ v. 11, n. 2,2015}

as etapas do estudo; resultados relativos à pesquisa bibliográfica, com a ressalva de que esta se encontra em andamento; considerações finais acerca do exposto.

\section{REFERENCIAL TEÓRICO}

Historicamente a Matemática é vista como difícil e chata pelos alunos, afirma Gómez-Granell (2006). De acordo com a autora, “aprender matemática significa aprender a observar a realidade matematicamente, entrar na lógica do pensamento e da linguagem matemática, usando as formas e os significados que lhe são próprios” (GÓMEZ-GRANELL, 2006, p. 282). Essa aprendizagem não é alcançada por muitas crianças.

Segundo Gómez-Granell, estudos têm constatado que a maioria dos alunos "não alcança o mínimo do conhecimento matemático necessário, ao final da escolaridade obrigatória” (2006, p. 257). Desse modo, nesse campo, a realidade assim se configura: "a matemática, um dos conhecimentos mais valorizados e necessários nas sociedades modernas altamente tecnologizadas é, ao mesmo tempo, um dos mais inacessíveis para a maioria da população" (GÓMEZ-GRANELL, 2006, p. 258).

Esse quadro justifica a pesquisa aqui focalizada, que propõe investigar o ensino de matemática em anos escolares que são cruciais para a construção de um sentimento positivo (ou negativo) com relação à mesma pelo aluno e das bases necessárias para a aquisição de conhecimentos posteriores. Não se trata de um olhar propedêutico, mas de reconhecer que o conhecimento matemático não aprendido hoje, sendo pré-requisito ao de amanhã, poderá prejudicar o rendimento do aluno, com reflexos em sua autoestima.

De acordo com Teixeira (2004), três podem ser as causas da não aprendizagem em Matemática: a natureza do conhecimento matemático; a natureza do ensino; os processos cognitivos do aluno. A primeira causa sugere retomar Gómez-Granell (2006) e sua premissa de que, a Matemática pode ser difícil, dada a linguagem formal que lhe é própria, mas não é incompreensível. Com relação à segunda, Teixeira entende que "ensinar matemática é fazer ao aluno um convite à abstração" (2004, p. 12). De modo mais abrangente, considera que “ensinar é negociar significados” (TEIXEIRA, 2004, p. 12). Retomando Gómez-Granell (2006), duas podem ser as posturas assumidas pelo professor que ensina Matemática, classificadas em: tendência sintática, que prioriza somente procedimentos; tendência semântica, voltada à compreensão de conceitos. Para Gómez-Granell (2006), é preciso haver 


\section{- Etinerarills Devista Eletrônica da Pós-Graduação ¿2 v. 11, n. 2,2015}

equilíbrio entre ambas. A terceira causa, por sua vez, sugere considerar aquele a quem se busca ensinar, suas linguagens, sua constituição enquanto ser cultural e social.

Além das dificuldades de aprendizagem e, por conseguinte, do baixo rendimento dos alunos, justifica a pesquisa a necessidade de repensar o currículo do curso de Pedagogia com relação à carga horária dedicada aos conhecimentos que permitem ao egresso ensinar Matemática com autonomia e segurança nos anos de alfabetização. Esse quadro é agravado pela relação precária dos alunos desse curso com a Matemática, conforme afirmam Lopes e Feitosa (2014), tornando-se latente a insegurança causada pela falta de um repertório que permita a esse futuro professor ensinar o conteúdo matemático.

Na perspectiva de Mizukami (1996), trata-se de considerar se os conhecimentos necessários para ensinar Matemática na Educação Infantil e nos anos iniciais do Ensino Fundamental compõem os quadros referenciais para a docência do egresso, pois, construídos a partir da experiência do licenciando na Educação Básica, esses quadros irão orientar suas ações pedagógicas futuras. De outro modo, o professor que não teve a oportunidade de ressignificar sua relação com a Matemática no curso superior poderá evitá-la ou conferir-lhe um tratamento qualquer, ancorando-se apenas, e de modo acrítico, no livro didático. Reflexos dessa sua trajetória estarão presentes em sala de aula.

Nesse caso, a negação do conhecimento matemático na Educação Infantil ou nos anos iniciais do Ensino Fundamental remete à Saviani (2012) e sua premissa de que a função da escola é propiciar ao aluno a aquisição dos conhecimentos historicamente produzidos pela sociedade. Para que essa função se concretize, é preciso ter professores devidamente formados e capazes de ensinar matemática.

Nesse ponto, cabe a ressalva de que a visão da matemática como "chata" e "sem sentido", distante da vida fora da sala de aula, é construída socialmente, o aluno não nasce compreendendo-a desse modo. Por isso se diz que a história do aluno com a matemática pode ser mudada, de maneira que finalmente a maioria (não mais a minoria) tenha acesso a esse conhecimento.

\section{METODOLOGIA}

Os pressupostos anteriormente apresentados fundamentam a pesquisa aqui focalizada, sendo a mesma de cunho qualitativo, assim conceituada a partir de Bogdan (2013), 


\section{- Petinerarius Devista Eletrônica da Pós-Gráduação

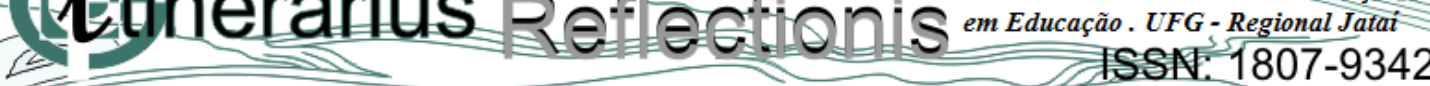 \\ v. 11, n. 2,2015}

realizada em duas etapas: primeira, pesquisa bibliográfica respaldada em Lakatos (2014); segunda, análise documental amparada em Gil (2011).

A primeira etapa tem como procedimentos básicos leitura orientada e produção de textos organizada em eixos temáticos coerentes com o tema investigado. A segunda, por sua vez, prevê leitura dos projetos pedagógicos das escolas públicas municipais urbanas ${ }^{3}$ localizadas na cidade de Jataí, sendo as categorias de análise definidas a posteriori, seguida de interpretação fundamentada Goded (1999), Gómez-Granell (2006) e outros.

Os resultados apresentados a seguir são relativos à primeira etapa, que, como dito, consiste na pesquisa bibliográfica, atualmente em andamento, de maneira que ao exposto serão acrescentados outros estudos.

\section{RESULTADOS}

Os resultados aqui apresentados são preliminares, fruto de leituras parciais sobre o tema. Permitem aproximações sobre o que é ensinar e aprender matemática nos primeiros anos escolares e quais os elementos envolvidos nesse processo, com destaque para abordagens de ensino.

Inicia-se retomando Gómez-Granell (2006), que aponta duas posturas assumidas pelo professor que ensina Matemática, a "sintática", que privilegia procedimentos, ou a "semântica", que prima pela compreensão do aluno acerca do conteúdo abordado em sala de aula.

A compreensão do conteúdo pelo aluno é objeto de estudos de Panizza (2006b). A autora afirma que "não é possível tratar o tema da aprendizagem e o ensino da matemática sem se referir seriamente à questão do sentido" (PANIZZA, 2006b, p. 19) e que "sentido" é uma palavra cada vez mais presente nas preocupações dos professores que se ocupam do ensino de matemática. Ao falar em "sentido", é preciso esclarecer "sentido de que" e identificar seus aspectos constitutivos. Por exemplo, ao terminar a escolaridade, é necessário (e desejável) que um aluno consiga reconhecer o número 6, não somente no numeral "6", mas também nas expressões " $18 / 3 "$, “4+2”, “5+1" ou “2x3”. Para trabalhar privilegiando esta abordagem, é preciso que o professor saiba diferenciar os objetos matemáticos de suas

\footnotetext{
3 A opção por escolas da zona urbana, excluindo-se, assim, as da zona rural, é feita a partir do critério acessibilidade, que envolve tempo e recursos disponíveis.
} 
representações e "compreenda as condições sob as quais uma representação funciona como tal" (PANIZZA, 2006b, p. 21).

Além de distinguir conceitualmente os objetivos matemáticos de suas representações, o professor necessita de saberes relativos à aprendizagem, que consistem em diferenciar procedimentos e maneiras de conhecer dos alunos, e saberes didáticos, que possibilitam reconhecer aspectos que permeiam e mecanismos que permitem a construção de sentido na aprendizagem matemática (PANIZZA, 2006b).

Os alunos têm maneiras de conhecer (implícitas ou explícitas) não reconhecidas pela escola, instituição que deveria "rever a postura tradicional que ignora o valor do uso de representações não-convencionais na aquisição do conhecimento matemático" (PANIZZA, 2006b, p. 24). Essa premissa coloca a necessidade de proporcionar aos alunos atividades com diferentes formas de representação (verbal, simbólica, icônica etc.), colocando-os em contato com "experiências que lhes permitam conhecer tanto o funcionamento dos sistemas simbólicos, como os diversos aspectos dos objetos matemáticos que estes permitem representar" (PANIZZA, 2006b, p. 29).

Propondo um ensino de matemática que faça sentido ao aluno, Panizza se refere à teoria das situações didáticas, de Guy Brousseau", compreendida como "teoria do ensino que busca as condições para uma gênese artificial dos conhecimentos matemáticos na hipótese que estes não são construídos espontaneamente" (2006a, p. 35), priorizando os conceitos de "situações adidáticas" e "institucionalização". Com relação ao primeiro, a autora esclarece que o termo designa

(...) toda situação que, por um lado, não pode ser dominada convenientemente sem colocar em prática os conhecimentos ou o saber que se pretende, e que, por outro lado, sanciona as decisões que o aluno toma (boas ou más) sem intervenção do professor no que concerne ao saber que se põe em prática (PANIZZA, 2006a, p. 36).

Toda situação adidática tem como características: o caráter de necessidade dos conhecimentos - inclui a noção de "variável didática", entendida como conjunto de elementos que podem afetar e, consequentemente, alterar uma situação didática; a noção de sanção - a situação adidática é concebida como um momento de aprendizagem e não de ensino; os

\footnotetext{
4 Para uma caracterização mais acurada da teoria das situações didáticas, conferir: BROUSSEAU, G. Introdução ao estudo da teoria das situações didáticas: conteúdos e métodos de ensino. São Paulo: Ática, 2008.
} 
alunos devem encontrar por si mesmos as relações entre as suas opções e os resultados que obtêm; a não intervenção do professor em relação com o saber - não significa que o professor se retire ou se transforme em expectador, suas intervenções servem para instalar e manter os alunos na tarefa.

A teoria de Brousseau comporta situações didáticas assim identificadas: situações de ação, em que o aluno atua sobre o meio; situações de formulação, que compreendem formulação e troca de mensagens entre os alunos; situações de validação, nas quais os alunos enunciam e justificam suas escolhas na resolução de problemas, com a finalidade de validálas. Desse processo faz parte a "institucionalização", anteriormente referida, que "supõe estabelecer relações entre os trabalhos dos alunos e o saber cultural, e não deve ser reduzida a uma apresentação do saber cultural em si mesmo desvinculado do trabalho anterior na sala de aula" (PANIZZA, 2006a, p. 40).

Ensinar matemática é um desafio, afirma Toledo (1997). Essa ação pode ocorrer de dois modos, o primeiro centrado na memorização e na reprodução de conteúdos.

\begin{abstract}
Alguns professores consideram que, sendo a matemática uma ciência hipotéticodedutiva, deve ser apresentada dessa maneira desde as fases iniciais. Assim, exigem das crianças um nível de abstração e formalização que está acima de sua capacidade, pois os quadros lógicos de seu pensamento não estão desenvolvidos o suficiente. A saída encontrada pelos alunos é memorizar alguns procedimentos que lhes permitem chegar aos resultados exigidos pelo professor (TOLEDO, 1997, p. 10).
\end{abstract}

O segundo modo privilegia a construção do conhecimento pelo aluno e se ampara conceitualmente em teorias cognitivistas e sóciocognitivistas.

\footnotetext{
Para outros professores, as regras de dedução, que caracterizam o raciocínio matemático do adulto, são construídas aos poucos, à medida que a criança interage com seu meio, com as pessoas que a cercam. Esses professores preferem adotar um método mais intuitivo, indutivo, em que são respeitados os conhecimentos já construídos pelo aluno, ao mesmo tempo em que lhe são dadas oportunidades de realizar experiências, descobrir propriedades, estabelecer relações entre elas, construir hipóteses e testá-las, chegando a determinado conceito. Em geral, os alunos desses professores são os que vêem a matemática com mais tranqüilidade e segurança (TOLEDO, 1997, p. 10).
}

Voltando o foco para o aluno, Lerner (1995) considera que as crianças aprendem matemática em situações que lhes permitem expor hipóteses, estratégias e procedimentos mobilizados para resolver determinado problema, aproximando-se, assim, do que preconiza a teoria de Brousseau. 
Centrada na aprendizagem, a autora investiga o que alunos, professores e pais pensam sobre a matemática e sua utilidade, a aprendizagem e o ensino de matemática, e conteúdos matemáticos difíceis, entre outros aspectos. Desse modo, constata que, para todos os professores entrevistados, a matemática provoca temor; para as crianças, é a disciplina que menos gostam, porque consideram que é complicada e não gostam de fazer contas.

No que concerne à utilidade da matemática, os professores afirmam que ela "tem importância, porque prepara a criança para raciocinar com rapidez e porque se deve saber utilizá-la na vida diária; é uma disciplina instrumental - como a leitura - que ajuda a compreender as demais matérias; é uma ciência "muito completa, porque é exata" (LERNER, 1995, p. 05). Para os pais, ela serve para fazer cálculos, orçamentos, resolver problemas e realizar outras tarefas cotidianas. Apesar das respostas obtidas, Lerner sublinha que "nem os pais, nem os professores têm conseguido transmitir às crianças - ao menos às mais pequenas - essa utilidade da matemática que alguns deles percebem tão claramente” (1995, p. 06).

No contexto da pesquisa de Lerner, as respostas sobre aprendizagem matemática indicam a coexistência de duas concepções na escola, uma pautada em descobrir, investigar, discutir, interpretar, outra em explicar, repetir, memorizar. De acordo com a autora, "muitos professores reconheceram que alguns conhecimentos matemáticos são construídos pelas crianças a partir da sua experiência social, e que a aprendizagem de certos conteúdos começa antes do ingresso na escola" (1995, p. 09).

Quanto ao ensino, todos os professores concordam que o êxito do mesmo está na repetição. Compartilham a concepção de que "ensinar consiste em explicar, aprender consiste em repetir (ou exercitar) o ensinado até reproduzi-lo fielmente" (LERNER, 1995, p. 11). O mesmo se verifica entre as crianças, a maioria é partidária do ensino tradicional e parece aceitar que são "meras repetidoras e não seres pensantes" (LERNER, 1995, p. 12), elas concebem o professor como alguém que reproduz o programa. Já os pais se mostram inclinados a pensar que seus filhos aprendem sozinhos.

Perguntados sobre os recursos que utilizam com crianças que apresentam dificuldades de aprendizagem, os professores respondem que apelam à repetição, a encaminhamentos ou pedem a colaboração dos pais. Embora se mostrem sensíveis a essas dificuldades, nem todos assumem o mesmo grau de responsabilidade. Pais, crianças e professores são unânimes em afirmar a importância dos primeiros no processo de aprendizagem, "todas as crianças assinalam que suas mães e às vezes também os pais e 
irmãos maiores desempenham um papel decisivo como "educadores"” (LERNER, 1995, p. 19).

As concepções investigadas por Lerner (1995) compõem o processo de ensinar e aprender matemática, na medida em que orientam as ações daqueles que dele participam. Confirmando essa perspectiva, Moreno afirma que "toda prática pedagógica está determinada por concepções sobre como se ensina e como se aprende" (2006, p. 43). Ao investigar o ensino de número e do sistema de numeração na Educação Infantil e no primeiro ano escolar, Moreno confirma a coexistência de enfoques distintos no ensino do conteúdo matemático, um deles é o "ensino clássico", segundo o qual "primeiro se ensinam as noções para que depois sejam aplicadas; isto é, considera-se que as crianças somente podem resolver problemas se previamente o professor lhes ensinou os procedimentos canônicos, como a escrita convencional dos números, as contas, etc.” (MORENO, 2006, p. 44).

Analisando a resolução de problemas por crianças em idade de alfabetização e compreendendo problemas como "situações que criam um obstáculo a vencer, que promovem a busca dentro de tudo o que se sabe para decidir em cada caso aquilo que é mais pertinente, forçando, assim, a utilização dos conhecimentos anteriores e mostrando-os ao mesmo tempo insuficientes e muito difíceis" (MORENO, 2006, p. 51), questiona

(...) qual seria o obstáculo que um aluno pode enfrentar se os problemas que lhe são oferecidos são sempre os mesmos? Por que se empenharia na busca de novos modos de resolução se com o que sabe consegue resolver? Como poderia decidir quais procedimentos utilizar se o professor lhe "dita" o que deve fazer? A aprendizagem termina, nesse caso, transformando-se em um ato de "fé": tem de fazer procedimentos, porque o professor lhe pede, tal e como lhe pede (MORENO, 2006, p. 51).

Dando continuidade, considera

(...) no ensino tradicional, depois da resolução do problema, o aluno tem acesso à correção individual por parte do professor. O aluno resolve e, depois do tempo necessário para que o professor corrija, recebe uma avaliação de seu trabalho com conceitos que podem variar entre 'muito bom', 'regular' e 'refazer', etc. No entanto, que informação a correção dá ao aluno em relação à sua resolução? Como faz para distinguir se se enganou no procedimento que escolheu para resolver o problema ou se o que está errado é o resultado que obteve? A ilusão que está por trás desse tipo de prática é supor que um aluno, somente pelo fato de observar o produzido, vai poder modificar sua ação (MORENO, 2006, p. 53).

Segundo Moreno, "na matemática, um mesmo problema pode ser resolvido com diferentes conhecimentos e um mesmo conhecimento pode resolver diversos problemas" 
(2006, p. 53). O trabalho com problemas deve começar cedo, já na Educação Infantil, "antes que os alunos disponham das soluções 'especialistas' para resolvê-los" (MORENO, 2006, p. $55)$.

Os questionamentos da autora se dirigem também ao "contar". Em suas palavras,

(...) do ponto de vista didático, um aluno que não possua os três princípios descritos ${ }^{5}$ não estaria capacitado para resolver problemas que impliquem contar e, portanto, não teria de apresentá-los? Como poderia aprender a contar se não lhe oferecemos um meio de problemas que o mostrem como necessário? É justamente por meio da resolução de problemas que um aluno poderá apropriar-se progressivamente do princípio de adequação única e, daí em diante, progredir até à possibilidade de cardinalizar uma quantidade (MORENO, 2006, p. 57).

Confirmando o que pressupõe Panizza (2006b), Moreno salienta que aprender matemática é "construir o sentido dos conhecimentos, e que são os problemas e a reflexão em torno destes que permitem a esses conhecimentos ganharem sentido quando aparecem como ferramentas para poder resolvê-los" (2006, p. 59). Para tanto, é preciso "propor aos alunos situações didáticas nas quais os números apareçam como ferramentas de resolução, isto é, que seja necessário usar os números em todos os contextos possíveis” (MORENO, 2006, p. 59).

\section{CONSIDERAÇÕES FINAIS}

Os resultados aqui apresentados são relativos à pesquisa bibliográfica em andamento, sendo esta a primeira etapa de uma investigação que prevê análise dos projetos pedagógicos das escolas municipais urbanas de Jataí, com foco no ensino de matemática nos dois primeiros anos escolares, que compreendem o período de alfabetização.

Embora inconclusa, a pesquisa bibliográfica aponta dois tipos de ensino, o tradicional ou "clássico", segundo Moreno (2006), e aquele que busca fazer com que a matemática tenha sentido ao aluno, primando, assim, pela compreensão do conteúdo. Da discussão sobre aprendizagem, emergem elementos como as representações nãoconvencionais do aluno sobre a matemática, verificadas, por exemplo, no uso de objetos (símbolos, desenhos etc.) para indicar quantidade, ao invés do numeral convencionalmente aceito pela Matemática, e a aceitação do ensino tradicional pelos alunos, numa quase identificação desses últimos com o mesmo, colocando em evidência a reprodução e a

\footnotetext{
${ }^{5}$ Princípio de adequação, princípio de cardinalidade e princípio de indiferença da ordem (MORENO, 2006).
} 


\section{Mtinerariuls Revista Eletrônica da Pós-Gráduação ¿2 \\ v. 11, n. 2,2015}

memorização do conteúdo matemático como finalidade do "fazer pedagógico" nessa área do conhecimento.

Voltando o foco ao professor, saberes são apontados àquele que pretende ensinar matemática de maneira que essa tenha sentido ao aluno. De modo geral, os estudos arrolados parecem convergir no que diz respeito a assunção de um novo olhar sobre como se ensina matemática e qual o lugar do aluno nesse processo. Outros fatores deverão surgir na continuidade da pesquisa bibliográfica, permitindo angariar elementos para análise documental, com foco na alfabetização matemática.

O diálogo com a literatura mantido até o momento inspira retomar as palavras de Gómez-Granell no ponto em que afirma que "saber matemática é uma necessidade imperativa numa sociedade a cada dia mais complexa e tecnológica" (2006, p. 257). Em face das mesmas, finaliza-se com o seguinte questionamento: se, historicamente, o rendimento dos alunos em Matemática não é satisfatório, por que insistir num ensino que tende a manter a "matematofobia”, assim nomeada por Trabal (2011), que em nada contribui para a superação desse dilema?

\section{REFERÊNCIAS}

BOGDAN, R. Qualitative research for education: on introduction to theory and methods. Boston: Allyn and Bacon, 2003.

GIL, A. C. Métodos e técnicas de pesquisa social. 6. ed. São Paulo: Atlas, 2011.

GODED, P. A. El conocimiento profesional: naturaleza, fuentes, organización y desarrollo. Quadrante - Revista Teórica e de Investigação, Lisboa, v. 8, p. 111-138, 1999.

GÓMEZ-GRANELL, C. A aquisição da linguagem matemática: símbolo e significado. In: TEBEROSKY, A.; TOLCHINSKY, L. Além da alfabetização: a aprendizagem fonológica, ortográfica, textual e matemática. 4. ed. São Paulo: Ed. Ática, 2006, p. 257282.

LAKATOS, E. M. Metodologia do trabalho científico: procedimentos básicos, pesquisa bibliográfica, projeto e relatório, publicações e trabalhos científicos. 7. ed. São Paulo: Atlas, 2014.

LERNER, D. A matemática na escola: aqui e agora. Porto Alegre: Artmed, 1995.

LOPES, R. P.; FEITOSA, E. O desafio de ensinar Matemática nos primeiros anos escolares com novas tecnologias e a formação do professor alfabetizador. In: CONGRESSO 
NACIONAL DE PROFESSORES, 2, 2014, Águas de Lindóia. Anais... Águas de Lindóia, SP: UNESP/Pró-Reitoria de Graduação, 2014, p. 6599-6610.

MIZUKAMI, M. G. N. Docência, trajetórias pessoais e desenvolvimento profissional. In: REALI, A. M. M. R.; MIZUKAMI, M. G. N. (Orgs.). Formação de professores: tendências atuais. São Carlos: EDUFSCar, 1996, p. 59-91.

MORENO, B. R. O ensino do número e do sistema de numeração na educação infantil e na $1^{\mathrm{a}}$ série. In: PANIZZA, M. (Org.). Ensinar matemática na educação infantil e nas séries iniciais: análise e propostas. Porto Alegre: Artmed, 2006, p. 43-76.

PANIZZA, M. Conceitos básicos da teoria de situações didáticas. In: PANIZZA, M. (Org.). Ensinar matemática na educação infantil e nas séries iniciais: análise e propostas. Porto Alegre: Artmed, 2006a, p. 35-41.

PANIZZA, M. Reflexões gerais sobre o ensino da matemática. In: PANIZZA, M. (Org.). Ensinar matemática na educação infantil e nas séries iniciais: análise e propostas. Porto Alegre: Artmed, 2006b, p. 19-33.

SAVIANI, D. Escola e democracia: teorias da educação, curvatura da vara, onze teses sobre a educação política. 42. ed. Campinas, SP: Autores Associados, 2012.

SILVA, T. T. Documentos de identidade: uma introdução às teorias do currículo. 2. ed. Belo Horizonte: Autêntica, 2003.

TEIXEIRA, L. R. M. Dificuldades e erros na aprendizagem da Matemática. ENCONTRO PAULISTA DE EDUCAÇÃO MATEMÁTICA, 7, 2004, São Paulo. Anais... São Paulo: SBEM, 2004, p. 1-14.

TOLEDO, M. Didática da matemática: como dois e dois - a construção da matemática. São Paulo: FTD, 1997.

TRABAL, P. Una sociología de la enseñanza de las matemáticas. Revista Educación y Pedagogía, v. 23, n. 59, jan./abr., p. 227-240, 2011.

VEIGA, I. P. A. Inovações e projeto político-pedagógico: uma relação regulatória ou emancipatória? Cad. Cedes, Campinas, v. 23, n. 61, p. 267-281, dez. 2003. 